\title{
A clínica vincular e suas bordas: o trabalho com grupos ${ }^{67}$
}

\section{Cristina A. J. Parada Franch 68}

Quando recebi o convite para este Simpósio logo me lembrei do artigo de um colega, Paulo Jerônimo Carvalho, que apontava para como nas últimas quatro décadas a teorização sobre grupos havia ficado num lugar recusado dentro das instituições psicanalíticas formais. Os grupos continuaram sendo feitos em abundância nas instituições de saúde, de educação, da justiça e em muitas outras, mas o estudo, a pesquisa e a formulação de sua metapsicologia foram ficando reduzidos.

Kaës, um dos poucos psicanalistas que se manteve ativo nessa formulação, escreve:

Minha tese é que o grupo tem constituído a matriz fecunda e traumática da invenção da psicanálise, de sua instituição e de sua transmissão: sua teoria e sua prática portam os traços dos enlaces passionais, sabidamente violentos e repetitivamente traumáticos que foram postos desde sua fundação. Esses lugares distintos se sobredeterminam uns aos outros, e essa imbricação não pensada mantém o grupo como questão indefinidamente suspensa, rejeitada e mal conhecida. A questão ganha valor de sintoma e produz a resistência epistemológica para transformar a afinidade conflituosa em problema na e para a psicanálise; ela também sustenta e inaugura a resistência epistêmica do psicanalista a se reconhecer como sujeito constituído e constituinte desta questão. Tudo se passa como se a mutação, que Freud descreveu, desde o regime psíquico e cultural da horda até o dele mesmo, civilizado e criador de pensamento, devesse ser constantemente recolocada em trabalho.

Foi um grande prazer encontrar nesse Simpósio um lugar para a discussão da teorização sobre os grupos, assim como das clínicas ampliadas. Parece que estamos conseguindo vencer a resistência institucional em um momento sóciopolítico-econômico tão importante de ser pensado tanto do ponto de vista do laço social como do campo sócio institucional. A polarização que vem acontecendo no tecido social tem provocado esgarçamentos e rupturas nas membranas institucionais, grupais, familiares e também nas dos grupos internos, do campo intrapsíquico. $\mathrm{O}$ aumento significativo de suicídios entre os jovens pode ser um exemplo disso. A cultura neoliberal em que estamos submersos estaria

\footnotetext{
67 Trabalho apresentado na mesa "A clínica vincular e suas bordas: o trabalho com grupos" no II Simpósio Bienal SBPSP "Fronteiras da Psicanálise: a clínica em movimento" no dia 22 de agosto de 2020.

68 Membro filiado da SBPSP, membro do Instituto Sedes Sapientiae, coordenou grupos e famílias e o núcleo de Transmissão e Investigação (Projetos Terapêuticos).
} 
contribuindo para essa polarização? Wladmir Safatle propõe que estaríamos sob a égide de um capitalismo cínico, em que a recusa, mecanismo da perversão, estaria predominante no funcionamento social. Como se estabelecem os contratos narcísicos quando o campo social está cindido e tomado pelo ódio? Acredito que a abertura de espaços para a conversa sobre o funcionamento dos grupos pode ser um começo para nos ajudar a elaborar esse sintoma de que fala Kaës e também contribuir para a elaboração do mal-estar desse momento da cultura.

Para aprofundar o pensamento sobre a intercomunicação entre as membranas social, institucional, grupal, familiar e individual (as fronteiras), sobre o funcionamento grupal e também sobre o contrato narcísico vou compartilhar com vocês um trabalho que escrevi sobre um microcosmo específico, que buscará ilustrar e apresentar algumas teorias que vim recolhendo ao longo dos muitos anos que trabalhei em instituições e com grupos.

O interesse pela loucura e pela potência do tratamento institucional, tão vívido nos anos 80, me levou a trabalhar em hospital psiquiátrico, ambulatório de saúde mental, centro de saúde, hospital dia e por último na instituição Projetos Terapêuticos, instituição de base psicanalítica para tratamento de casos graves. Foi nessa última, onde trabalhei por 17 anos, que pude me dedicar à costura da experiência vivida com as teorias da psicanálise que podiam dar sustentação à compreensão do campo grupo-institucional.

O Projetos Terapêuticos será o microcosmo de referência e as questões que serão trabalhadas são: por quê a recepção dos novos pacientes mobiliza tanta angústia e sensação de incapacidade na equipe? O que nos imobilizava na constituição de um setting contornado para receber os nossos rebentos? Por que costuma ser tão difícil para as famílias adoecidas fazerem um contrato de tratamento com a instituição. As fronteiras entre o privado e o público.

Os Começos: a re(de)cepção e os contratos (im)possíveis.

A constituição de um setting institucional é trabalho contínuo. Organismo vivo, a instituição pulsa de acordo com a maturidade e constituição da equipe, com a sintomatologia do que trata, com o discurso do meio ao qual está inserida, com o modelo cultural vigente e com tantas outras variáveis. Este trabalho tem a intenção de pensar as transformações que ocorreram no dispositivo de recepção em uma instituição, de base psicanalítica, que trata a psicose e os casos graves. A 
percepção de que a recepção é momento delicado e privilegiado nos move a pensar e teorizar as dificuldades dessas famílias em constituir um contrato com a instituição/campo social, as dificuldades institucionais em estabelecer um contrato com essas famílias e o quê das formações familiares fica projetado no campo institucional impedindo que esses "infans"- adultos façam a passagem do privado para o público.

Os começos... Durante os primeiros anos, de uma instituição que já tinha 15, a recepção dos pacientes ficava colocada num lugar fugidio, da ordem do recusado, quem os recebia se sentia sob uma enorme exigência e era geralmente tomado por um sentimento de incapacidade. Aos poucos fomos encontrando no compartilhamento das dificuldades uma saída, não precisávamos mais ficar sozinhos com a decepção e com a exigência, mas podíamos dividir e assim constituir um setting composto pelos mais "velhos", com mais experiência. Essa passagem ocorre no momento em que a instituição consegue fazer discriminações mais claras das diferenças geracionais e distribuir as tarefas em camadas que desafogam o diretor clínico de um lugar total, atemporal.

A experiência clínico-institucional com casos graves nos alerta para o que reproduzimos na cena institucional dos sintomas daqueles que tratamos. A teoria Blegeriana toma um sentido encarnado na experiência vivida, tanto a ideia de que o setting é depositário das partes mais primitivas, psicóticas, daqueles que tratamos, como a de que a instituição reproduz o sintoma de que trata, faz-nos pensar que ao evitar uma aproximação mais contornada com a recepção, reproduzíamos algo do recusado nessas famílias.

Os começos... em seu trabalho sobre o Contrato Narcísico, Piera Aulagnier propõe que "nos começos" o grupo familiar e a criança são signatários de um contrato em que o investimento da criança pelo grupo antecipa o investimento do grupo pela criança. O grupo investiria a criança como voz futura, ela seria solicitada a repetir os enunciados de uma voz morta e garantir desta forma a permanência qualitativa e quantitativa de um corpo que se auto regenera de maneira contínua. A criança, em contrapartida, pedirá que lhe assegurem o direito de ocupar um lugar independente do veredicto parental, pedirá que lhe seja oferecido um modelo ideal que os outros não possam renegar sem renegar as leis do meio. 
O discurso do meio oferece ao sujeito uma certeza sobre a origem que é necessária ao acesso de uma dimensão histórica que por sua vez é essencial ao processo identificatório que lhe trará a autonomia necessária para a vida.

O que o meio oferece ao sujeito singular o levará a transferir uma parte do investimento narcísico de seu jogo identificatório sobre este grupo que lhe oferece uma recompensa futura: escapar ao veredito do tempo. O tempo futuro, quando o sujeito não mais existir, lhe fará acreditar que uma nova voz virá dar vida ao seu próprio discurso (pg. 151).

Para Piera a função de padrinhos sociais será exercida pelo casal parental que investe em um modelo futuro, em um projeto identificatório que estaria diretamente vinculado a um Eu capaz de assumir a experiência de castração e renunciar ao atributo de certeza sem renunciar a esperança do vir a ser, que não poderia faltar e deveria ser valorizada pelo sujeito e pelo meio.

Cena 1 - Paulo, até o nascimento, era para ser Paula, "o quarto já estava pronto... por sorte eram cores neutras... deu para aproveitar”, diz a mãe. Isso é compartilhado após seis meses em processo de recepção. A comunicação é feita como se nada fosse, o afeto que aparece é a euforia. A família nos procura quando Paulo tinha 18anos, um autismo inicial se apresentava agora como uma psicose. Paulo era habitado por muitas vozes que o dividiam internamente e dificultavam a comunicação, os muitos tiques o tornavam uma figura estranha e simpática.

Naquele momento Paulo se encaminhava para a programação institucional, para o grupo dos irmãos. Pouco tempo depois dessa comunicação ter sido feita, vivemos uma cena na reunião de equipe em que um desinvestimento abrupto da equipe à sua entrada acontece. Isto acontece logo após um representante da figura paterna na equipe ter solicitado a entrada rápida de uma moça que tinha mais recursos nos grupos. A decepção...de quem? A cena institucional se arma e a terapeuta que faz a recepção vive o horror de ficar sozinha, colada em Paulo.

No encontro infans-mãe, a mãe funcionaria como porta-voz tanto como aquela que o incluem em um discurso que comenta, prediz e acalenta suas manifestações, como representante de uma ordem exterior cujo discurso enuncia suas leis. A mãe oferece um material psíquico que só é estruturante porque já remodulado por sua própria psique, material que respeita as exigências da repressão. A oferta de um já reprimido será transformada em um ainda não 
reprimido para só voltar a ser o que dele fará a repressão porque encontra, quando da repressão, uma forma que já foi sua.

Piera segue dizendo que o desejo do pai investe a criança como sinal de que seu próprio pai não o castrou, nem o odiou, reconhecendo que ele morrerá não devido ao ódio do filho, nem como punição por ter odiado seu pai, mas porque, aceitando reconhecer-se como sucessor e aceitando reconhecer um sucessor, ele aceita legar, um dia, à este último, a sua função. Ele vê no filho aquele que confirma que a morte é consequência de uma lei universal e não o preço que paga por seu próprio desejo de morte de seu pai.

Desta forma a definição dada ao contrato narcísico implica em sua universalidade já que todo sujeito seria cossignatário deste. Levando sempre em consideração a variação da libido narcísica investida por cada sujeito e por cada casal na contratação. Dentro de certos limites, as variações casal-meio vão ocupar um papel secundário no destino do sujeito. Entretanto, se esses limites não forem respeitados, a ruptura do contrato pode ter consequências diretas sobre o destino psíquico da criança. A ruptura pode acontecer tanto por parte do casal que recusa as cláusulas essenciais do contrato, como por parte do meio que oferece ao casal um contrato já viciado, recusando-se a reconhecer o casal como autêntico representante do meio.

No primeiro caso ocorreria uma recusa total da mãe, do pai, ou de ambos em engajar-se ao contrato, o que revelaria a grave falha psíquica destes, um núcleo psicótico mais ou menos compensado. Seriam famílias que em seu fechamento "guardam seu louco" em um microcosmos para preservar um equilíbrio instável que se manteria enquanto fosse possível evitar o discurso dos outros "através do silêncio ao que se fala lá fora”.

No segundo caso, a ruptura de contrato seria responsabilidade do meio. Acontecimentos vividos pelo casal, que podem atingir o corpo, durante a infância do sujeito, o discurso dirigido à criança e as injunções que lhe foram feitas, assim como a posição de excluído que a sociedade impõe ao casal ou à criança, são chamado por Aulagnier de realidade histórica. Seriam situações que poderiam levar à ruptura de contrato e à psicose.

Assim nos procuram esses grupos familiares, fechados em microcosmos rompidos de formas e intensidades diversas com o contrato que os inseriria no campo social. O rompimento com o projeto de futuro estaria diretamente ligado 
com as interdições primordiais que não puderam ser metabolizadas na chegada desses novos membros já que estes apresentam-se mergulhados em patologias vinculares e familiares que se desdobram na impossibilidade da vida social e dos vínculos culturais. A passagem do indivíduo à série e da série à cultura, à comunidade dos irmãos, seria o caminho de constituição de um envoltório psíquico que fizesse frente à rivalidade fraterna, aos sentimentos hostis e pensamentos assassinos que uns têm pelos outros. Entretanto estes apresentamse em estados primitivos da psique cujas fronteiras mal definidas criam zonas indistintas entre o si mesmo e os outros.

Em Sobre o narcisismo: uma introdução (1914), Freud dirá que "sua majestade o bebê" foi sonhado pela mãe quando estava em seu ventre e já antes de se fixar ali, por ela, pelo pai e por todo o grupo familiar; o filho é sonhado como portador da esperança de realizar os desejos irrealizados daqueles que o precederam. Seu psiquismo está inscrito na organização onírica inconsciente do casal e da família, o berço onírico, para Kaës. Serão as falhas que ocorrem nesse espaço e com os processos que o sustentam que criarão as zonas de indistinção entre eu-outro.

Para Missenard (1985) a chegada de um recém-nascido provoca movimentos regressivos nos membros de uma família, colocando-os em contato com as partes infantis de sua própria história e, sobretudo, com os mitos familiares nos quais estão representadas as figuras ancestrais e o lugar que os filhos devem ocupar na família. Conclui dizendo que o que não pôde ser representado na psique materna será deslocado para a psique da criança. Ruffiot (1981) dirá que, nas famílias com sintomatologia psicótica, o modo de existência predominante caracteriza-se por se libertar da corporeidade individual, negando as diferenças sexuais e intergeracionais. Kaës (2004) dirá que as inscrições que deixaram traços na psique do pai ou da mãe, mas que não puderam ser representadas e transformadas por um processo de simbolização primária, não poderão reaparecer nos sonhos da criança.

Os começos... a impossibilidade de inscrição no contrato narcísico, quando do nascimento de um novo membro de uma família, estará diretamente vinculada aos excessos que não puderam ser metabolizados, sonhados e simbolizados. Estes ficam congelados e são transmitidos naquela linhagem familiar através das gerações. Nossa escolha de trabalhar com grupos em instituição encontra sua 
origem na soma de alguns vetores. Pensamos a instituição como campo intermediário, membrana plástica que facilitaria a passagem do privado para o campo social ao se manter em contínuo movimento de auto pensamento. Acreditamos que os grupos carregam em si uma condição que favorece a experiência onírica.

Anzieu (1966) defenderá a tese de que "os sujeitos humanos vão a grupos da mesma maneira que, em seu sono, entram a sonhar”. A cena intrapsíquica, onde o sonho é elaborado, se deslocaria para a cena do grupo, onde é representado. Supõe que o grupo, como o sonho, é um aparelho de transformação psíquica; entretanto, para que o sonho seja produzido será necessária a constituição de um espaço psíquico grupal comum e compartilhado. Para pensar essa constituição, Anzieu recorrerá ao conceito winnicottiano de espaço transicional em que se forma a ilusão da criança e que supõe uma experiência subjetiva e intersubjetiva de tolerância e confiança, em que coexistam o dentro e o fora, o eu e o não eu, o já presente e o ainda não advindo. Experiência esta da ilusão fundadora que conterá o tempo da desilusão, que anunciará a diferenciação. O mesmo ocorrerá no espaço grupal: à medida que a experiência da ilusão é possível, o grupo será lugar de uma experiência prévia à simbolização e à diferenciação; a ilusão envolverá o grupo em uma membrana fértil, continente, protetora e filtrante, necessária para as aproximações com o mundo externo em seu trabalho de diferenciação. Será o envoltório necessário para que as cenas oníricas se produzam e que sua figurabilidade comece a criar novas representações

Os começos...nos começos da Instituição Projetos Terapêuticos escolhemos como norte a concepção de uma instituição não-toda, em que a castração estivesse presente como emblema identificatório. Já antevíamos os riscos de tratar psicopatologias narcísicas em que suas projeções maciças poderiam nos congelar em funcionamentos totais. Pensamos que a condição de tratamento estaria ligada à possibilidade de constituição de settings contornados que suportassem a projeção daquilo que não pôde ser representado nos grupos familiares e à contínua atenção e pensamento sobre aquilo que estávamos encenando nas reproduções oníricas.

Desta forma vamos experimentando as intensidades da recepção em nossos próprios corpos, no corpo da equipe e da instituição. O que se reedita? 
Cena 2 - João toma conta de nossas reuniões de equipe seguidamente, não temos espaço para mais nenhum paciente, os terapeutas que fazem a recepção são assolados pela terrível angústia de morte e o suicídio é ameaça constante. Muitos telefonemas para compor alguma rede de continência à disrupção. Até que vamos conseguindo metabolizar aquilo que era indizível, da ordem do recusado... vamos nos sentindo abusados. $\mathrm{O}$ abuso começa a ser representado, primeiro na experiência corporal da equipe, desconforto, excesso... Quando conseguimos dar nome ao desconforto que encenávamos, aquilo que era falado, como se nada fosse, toma a proporção de sofrimento e pode ser representado em palavras encarnadas. As interdições começam a acontecer. Os terapeutas falam de um lugar transformado.

O equilíbrio instável dos grupos familiares que nos procuram é rompido ao trazerem à público o adoecimento de suas formas de funcionamento Ao recusar, inicialmente, a criação de um setting para dar conta de tal rompimento, o corpo institucional reproduzia algo da impossibilidade dessas famílias no recebimento desses filhos e de sua inscrição no contrato narcísico. Percebemos que o tempo da recepção até a chegada nos grupos do programa é um tempo lento, por vezes desistente. Aquilo que não pode ser representado na psique dos pais precisa ser representado e muitas vezes encenado pela equipe para que alguma passagem se estabeleça entre o fechamento dessas famílias e a entrada nos grupos. Para Fraiberg (1993) os fracassos dos primeiros encontros produzem um afeto de "decepção narcísica primária" que mobilizam mecanismos de defesa primitivos nos quais se reconhecem em um extremo as primeiras formas de retração da subjetividade numa linhagem autística e no outro as tentativas de cicatrização por meio de um masoquismo primário exacerbado. Entre as duas se situariam processos psicóticos, borderline, perversos ou antissociais.

Para abrir nosso debate, volto então à questão inicial. Como estão se estabelecendo os contratos narcísicos nesse momento em que o tecido social está tão esgarçado, e que as incertezas da continuidade ameaçam os projetos de futuro? Que discurso o meio está oferecendo para "os começos" daqueles que chegam? Penso que só o movimento coletivo, não de massa, poderá ter a força para nos levar à produção de uma membrana social contornada capaz de conter o reconhecimento e a valorização da alteridade e a projeção de um sonho coletivo de um futuro melhor para as novas gerações. Um sonhar coletivo que inclua a 
preocupação com a redução da desigualdade extrema, com a proteção ao meio ambiente, com a inclusão dos refugiados e tantas outras. Quem sabe a experiência da pandemia e do confinamento contribua para esse tipo de reflexão.

\section{Referências}

Anzieu, D. (1966) Le groupe et l'inconscient (1975). Paris: Dunod.

Bleger, J. (1979) O grupo como instituição e o grupo nas instituições. In Temas de psicologia - entrevista e grupos (1989). Trad. Rita Maria M. De Moraes. São Paulo: Martins Fontes.

Castoriadis-Aulagnier, P. (1975) A violência da interpretação (1979). Trad. Maria Clara Guimarães Pellgrino. Rio de Janeiro: Imago.

Fraiberg, S. (1993). Mécanismes de défenses pathologiques au cours de la petite enfance. In Devenir, 5(1), 7-29. Paris.

Freud, S. (1900/o1) La interpretación de los sueños. In Freud, S. (1979). Obras Completas, vol. 4 e 5. Trad. José Luis Etcheverry. Buenos Aires: Amorrortu Editores.

Freud, S. (1913/14) Tótem y tabu. In Freud, S. (1979). Obras Completas, vol. 13. Trad. José Luis Etcheverry. Buenos Aires: Amorrortu Editores.

Freud, S. (1914) Introducción del narcisismo. In Freud, S. (1979). Obras Completas, vol. 13. Trad. José Luis Etcheverry. Buenos Aires: Amorrortu Editores.

Freud, S. (1921) Psicologia de las masas y análisis del yo. In Freud, S. (1979). Obras Completas, vol. 18. Trad. José Luis Etcheverry. Buenos Aires: Amorrortu Editores.

Kaës, R. (1993) O grupo e o sujeito do grupo: elementos para uma teoria psicanalítica do grupo (1997). Trad. José de Souza e Mello Werneck. São Paulo: Casa do Psicólogo.

Kaës, R. (1999) Las teorias psicoanalíticas del grupo (2000). Trad. Mirta Segoviano. Buenos Aires: Amorrortu Editores.

Kaës, R. (2002) A polifonia do sonho (2004). Trad. Claudia Berliner. São Paulo: Ideias e Letras. 
Meltzer, D. (1992) The Claustrum - An Investigation of Claustrophobic Phenomena. Gloucesters: The Roland Harris Trust Library.

Meltzer, D. (1993) Le monde vivant du rêve. Lyon: Césura.

Missenard, A. (1985) Rêves de l'un, rêves de l'autre. In Psychiatries, 67, 4, p. 4358. Paris.

Ruffiot, A. (1981) Le groupe famille en analyse. L'appareil psychique familial. In A. Ruffiot, A. Eiguer et al., La thérapie familiale psychanalytique. Paris, Dunod. Ruffiot, A. Le groupe famille en analyse. L'appareil psychique familial. In: RUFFIOT, A. et al. La thérapie familiale psychanalytique. Paris: Dunod, 1981. Silveira, F. - Carvalho, P. J. P. (2010) A experiência clínica grupal e o modelo psicanalítico. In Revista Percurso 44 ano XXIII. O bem-e o mal-estar. 